\title{
Quality of life of patients with congenital heart diseases
}

\author{
Ana M. Silva, Cláudia Vaz, Maria E. G. Areias, Daniela Vieira, Cidália Proença, Victor Viana, \\ Cláudia Moura, José C. Areias \\ Department of Psychology, University of Porto, Instituto Superior de Ciências da Saúde do Norte (CESPU), \\ Cardiology Service, Hospital São João, Porto Medical School, Gandra, Portugal
}

\begin{abstract}
Objectives: To assess the perception of the quality of life of adolescents and young adults with congenital heart disease and to examine the variables that have a negative impact on it and that add a resilience effect. Methods: A total of 22 male and 18 female patients, aged 12-26 years, of whom 27 were admitted to surgery and 13 were not, participated in this study. All patients had complete medical records and were interviewed once; demographic and clinical data were collected, and patients filled a questionnaire on quality of life, the WHOQOL-BREF, and underwent an interview on social support, educational style, self-image, functional limitations, and emotional adjustment. Results/Conclusions: Our patients showed a better perception of quality of life than did the general population, on the basis of psychological, social relationship and environment scales. Older patients hold a better perception of quality of life on the psychological scale. Cyanosis did not show any significant impact over perception of quality of life decay; however, the number of surgical procedures and the persistence of moderate-to-severe residual injuries had considerable detrimental effect. Social support had an impact on increasing resilience, promoting adjustment to illness. Several factors may play a role in adjustment to congenital heart disease, either improving the perception of quality of life or worsening it. We may conclude that some buffer variables on congenital heart disease may play roles in increasing the perception of quality of life of patients during their lifetime, social support probably explaining why the perception of quality of life is better than in the normal population. The number of surgeries and the moderate-to-severe residual injuries, however, reverted that effect.
\end{abstract}

Keywords: Adolescents and young adults; risk and resilience factors; psychosocial aspects

Received: 2 March 2010; Accepted: 3 April 2011

$\mathrm{T}$ HE CONCEPTS OF QUALITY OF LIFE AND HEALTHrelated quality of life have been gaining importance in the present society since lethal diseases have become chronic, even though they often compromise the lifestyle of patients who are admitted to more intensive and invasive treatments. ${ }^{1}$

Technological progress has enabled earlier diagnosis, the enhancement of surgical techniques, and the consequent improvement in therapy results, thus increasing patients' survival. ${ }^{2,3}$

Correspondence to: M. E. Areias, Department of Psychology, University of Porto, Instituto Superior de Ciências da Saúde do Norte (CESPU), Rua Central de Gandra, 1317, 4585-116 Gandra Paredes, Portugal. Tel: 00351224157100 ; Fax: 003512241571 02; E-mail: metega@netcabo.pt
The increase in the survival rate of individuals with congenital heart disease created the need to analyse the quality of life in this group of patients as a way to assess treatment and also to prepare patients, relatives, and medical and social services to the potential difficulties encountered while confronting disease or while carrying out treatment along the patients' lifetime. ${ }^{1}$ The study of the quality of life in this group of patients also aims at assessing how and when clinical changes and/or health procedures can interfere in the life of the patients. ${ }^{3}$

Congenital heart disease includes a wide array of heart defects with different degrees of severity and a reported prevalence of eight per 1000 live births. The type of defect may affect the evolution of the 
disease, its prognosis, and the patients' ability to carry out their normal functions, ${ }^{4}$ thereby affecting their quality of life. Moreover, advances in paediatric cardiac care have resulted in an increasing number of adolescents and adults with congenital heart disease.

Taking into account the different levels of severity, there are studies that suggest that patients with congenital heart disease have a worse quality of life compared with the general population. ${ }^{3,5,6}$ However, others state that a deficient quality of life is found only in those with severe congenital heart disease and that the quality of life of patients with moderate cardiac disease is the same as that of the population in general. ${ }^{7}$ Still other researchers refer to a worse quality of life in only a few areas: motor functioning, $3,8-11$ cognitive functioning, ${ }^{9}$ emotional functioning, ${ }^{11}$ general health, ${ }^{10}$ and autonomy. ${ }^{9}$

Some findings are contradictory, with researchers advocating that quality of life and cardiac disease are not significantly related, ${ }^{4,12,13}$ sustaining that cardiac diseases do not influence the quality of life of patients.

Taking into account the contradictions of previous studies, the objective of our work was to verify whether the quality of life of our patients suffers the influence of different factors, whether or not caused by cardiac disease.

\section{Methods}

\section{Participants}

In all, 40 congenital heart disease patients, 22 male and 18 female, 27 submitted to surgery and 13 not submitted, were included in the study. They were recruited at the Outpatient Cardiology and Paediatric Cardiology Units of Hospital São João. The participants were selected randomly earlier by cardiologists, taking into account the goals of the study and its inclusion criteria.

\section{Data collection tools}

We have used an identification sheet comprising demographic data, namely age, marital status, educational level, profession, and household, and a clinical file with disease-related information, such as the diagnosis, severity, and type of cardiac disease, the need for surgical intervention and pharmacological therapy, as well as residual lesions. We have also used a semi-structured interview and a questionnaire, WHOQOL-Bref, on the perceived quality of life.

The interview was an original one, designed specifically for this study, based on a bibliographic research that allowed us to organise it around specific areas and to build up the items within each area.
The interview comprised 27 questions, some of which were multiple-choice and others short-answer, addressing different areas of the individual's life, such as the family environment, the social support network, functional limitations, progression through school, and satisfaction with body image.

The WHOQOL-Bref questionnaire includes 26 questions, with the first two being general - quality of life general - and the remaining 24 being divided into four different domains: physical (questions 3, $4,10,15,16,17$, and 18), psychological (questions $5,6,7,11,19$, and 26), social relationships (questions 20, 21, and 22), and environment (questions 8, 9, 12, 13, 14, 23, 24, and 25).

Each question can be scored from 1 to 5, where a higher score of 5 indicates a better quality of life, except for those questions that are not formulated in a positive manner (questions 3, 4, and 26), for which higher scores indicate a worse quality of life.

For each domain, the average of the questions has to be calculated and finally the results have to be transformed into a scale from 0 to 100 ; the user manual and the syntax for the WHOQOL-Bref tool in Portuguese may be obtained at http://www. fpce.uc.pt/saude/whoqolbref.htm.

\section{Statistical procedures}

Statistical processing and analysis were carried out with the help of the Statistical Package for the Social Sciences (SPSS) software, version 16.

We used a set of procedures according to the goals of the study to carry out statistical processing: Student's $t$-test; the Mann-Whitney test, and the Chi-square.

\section{Results}

We characterised our patients on the basis of the several domains of the quality of life. Table 1 presents the values obtained for each of the domains, comparing them with the reference values obtained for a healthy Portuguese population - article from the psychometric studies using the WHOQOL-Bref Tool for the Portuguese Population ${ }^{14}$ - using the one-sample " $t$ "-test procedure.

The congenital heart disease patients of our sample showed a better perception of quality of life for the psychological, social relationship, and environment domains, when compared with the healthy Portuguese population (Table 1).

Regarding the demographic variables, our patients have shown differences in age for the psychological domain, with older patients presenting a better perception of quality of life (Table 2). No differences 
were found in the perceived quality of life between male and female patients in the sample.

With regard to clinical variables, patients who were not admitted to surgery reported a better perception of quality of life for the physical domain (Table 3).

When we compare the quality of life among patients by considering the number of surgical procedures, and using one surgery as cutoff point (see Table 4), patients who were admitted to more than one surgery reported a worse quality of life for the physical domain as well.
With regard to residual lesions, patients with severe-to-moderate lesions exhibited a worse perception of quality of life when compared with individuals with light residual lesion differences, for the physical and psychological domains and for the general quality of life (Table 5).

No other clinical variable - presence or absence of cyanosis, severity of disease, and need for pharmacological therapy - showed any influence on the perceived quality of life in our congenital heart disease patients.

Finally, with regard to psychosocial variables personal resources, family environment, and social

Table 1. Means and standard deviations for the four domains of quality of life and quality of life general.

\begin{tabular}{lllll}
\hline Domains of quality of life & $\mathbf{M}\left(\mathbf{R V}^{*}\right)$ & DP & $\boldsymbol{t}$ & p-value \\
\hline Physical & $75.00(77.49)$ & 15.064 & -1.045 & 0.302 \\
Psychological & $78.20(72.38)$ & 12.445 & 2.958 & $\mathbf{0 . 0 0 5 * *}$ \\
Social Relationships & $79.55(70.42)$ & 16.294 & 3.544 & $\mathbf{0 . 0 0 1 * *}$ \\
Environment & $71.40(64.89)$ & 14.078 & 2.925 & $\mathbf{0 . 0 0 6}$ \\
QOL general & $74.25(71.51)$ & 16.32 & 1.062 & 0.295 \\
\hline
\end{tabular}

$\mathrm{DP}=$ standard deviations; $\mathrm{M}=$ means; $\mathrm{QOL}=$ quality of life; $t=$ degrees of freedom

$*$ Reference values for the Portuguese population without disease

$* * \mathrm{p}<0.01$

Table 2. Student's t-test for the four domains of quality of life and Mann-Whitney test for the general quality of life in different age groups.

\begin{tabular}{|c|c|c|c|c|c|c|}
\hline & \multicolumn{2}{|c|}{ From 12 to 18 years $(n=21)$} & \multicolumn{2}{|c|}{ From 19 to 26 years $(n=19)$} & \multirow[b]{2}{*}{$t$} & \multirow[b]{2}{*}{ p-value } \\
\hline & $\mathbf{M}$ & DP & $\mathbf{M}$ & DP & & \\
\hline \multicolumn{7}{|c|}{ Domains of quality of life } \\
\hline Physical & 15.66 & 2.257 & 16.34 & 2.520 & -0.900 & 0.374 \\
\hline Psychological & 15.82 & 1.964 & 17.31 & 1.773 & -2.502 & $0.017 *$ \\
\hline Social relationships & 16.44 & 3.094 & 17.12 & 1.951 & -0.819 & 0.408 \\
\hline Environment & 15.36 & 2.367 & 15.26 & 1.968 & 0.146 & 0.885 \\
\hline & \multicolumn{2}{|c|}{ Mean rank } & \multicolumn{2}{|c|}{ Mean rank } & $z$ & p-value \\
\hline QOL general & \multicolumn{2}{|c|}{18.95} & \multicolumn{2}{|c|}{22.21} & -0.929 & $0.035 *$ \\
\hline
\end{tabular}

$\mathrm{DP}=$ standard deviations; $\mathrm{M}=$ means; $\mathrm{QOL}=$ quality of life; $t$ and $z=$ degrees of freedom

$*_{\mathrm{p}}<0.05$

Table 3. Student's t-test for the four domains of quality of life and Mann-Whitney test for the general quality of life according to the need for surgical intervention.

\begin{tabular}{|c|c|c|c|c|c|c|}
\hline & \multicolumn{2}{|c|}{ Submitted to surgery $(n=27)$} & \multicolumn{2}{|c|}{ Without surgery $(n=13)$} & \multirow[b]{2}{*}{$t$} & \multirow[b]{2}{*}{ p-value } \\
\hline & M & DP & $\mathbf{M}$ & DP & & \\
\hline \multicolumn{7}{|c|}{ Domains of quality of life } \\
\hline Physical & 15.50 & 2.589 & 16.98 & 1.502 & -2.292 & $0.028 *$ \\
\hline Psychological & 16.33 & 2.098 & 16.92 & 1.784 & -0.872 & 0.389 \\
\hline Social relationships & 16.49 & 2.664 & 17.33 & 2.480 & -0.954 & 0.346 \\
\hline \multirow[t]{2}{*}{ Environment } & 15.01 & 2.358 & 15.96 & 1.561 & -1.324 & 0.193 \\
\hline & & Mean rank & \multicolumn{2}{|c|}{ Mean rank } & $z$ & p-value \\
\hline QOL general & & 18.57 & \multicolumn{2}{|c|}{24.50} & -1.584 & 0.113 \\
\hline
\end{tabular}

$\mathrm{DP}=$ standard deviations; $\mathrm{M}=$ means; $\mathrm{QOL}=$ quality of life; $t$ and $\mathrm{z}=$ degrees of freedom

$*_{\mathrm{p}}<0.05$ 
Table 4. Student's $t$-test for the four domains of quality of life and Mann-Whitney test for quality of life in general according to the number of surgeries.

\begin{tabular}{|c|c|c|c|c|c|c|}
\hline & \multicolumn{2}{|c|}{ One surgery $(n=20)$} & \multicolumn{2}{|c|}{ More than one $(n=19)$} & \multirow[b]{2}{*}{$t$} & \multirow[b]{2}{*}{$\mathrm{p}$-value } \\
\hline & M & DP & $\mathbf{M}$ & DP & & \\
\hline \multicolumn{7}{|c|}{ Domains of quality of life } \\
\hline Physical & 15.50 & 2.589 & 16.98 & 1.502 & -2.292 & $0.028 *$ \\
\hline Pychological & 16.33 & 2.098 & 16.92 & 1.784 & -0.872 & 0.389 \\
\hline Social relationships & 16.49 & 2.664 & 17.33 & 2.480 & -0.954 & 0.346 \\
\hline Environment & 15.01 & 2.358 & 15.96 & 1.561 & -1.324 & 0.193 \\
\hline & \multicolumn{2}{|c|}{ Mean rank } & \multicolumn{2}{|c|}{ Mean rank } & $z$ & p-value \\
\hline QOL general & \multicolumn{2}{|c|}{23.55} & \multicolumn{2}{|c|}{17.45} & -1.741 & 0.082 \\
\hline
\end{tabular}

$\mathrm{DP}=$ standard deviations; $\mathrm{M}=$ means; $\mathrm{QOL}=$ quality of life; $t$ and $z=$ degrees of freedom ${ }^{*} \mathrm{p}<0.05$

Table 5. Student's $t$ test for the four domains of quality of life and Mann-Whitney test for quality of life general according to severity of residual lesions.

\begin{tabular}{|c|c|c|c|c|c|c|}
\hline & \multicolumn{2}{|c|}{ Severe or moderate $(n=20)$} & \multicolumn{2}{|c|}{ Light $(n=20)$} & \multirow[b]{2}{*}{$t$} & \multirow[b]{2}{*}{ p-value } \\
\hline & $\mathbf{M}$ & DP & M & DP & & \\
\hline \multicolumn{7}{|c|}{ Domains of quality of life } \\
\hline Physical & 15.08 & 2.573 & 16.88 & 1.815 & -2.556 & $0.015 *$ \\
\hline Psychological & 15.85 & 2.043 & 17.20 & 1.751 & -2.244 & $0.031 *$ \\
\hline Social relationships & 16.27 & 2.913 & 17.27 & 2.215 & -1.222 & 0.23 \\
\hline Environment & 14.73 & 2.448 & 15.90 & 1.691 & -1.755 & 0.088 \\
\hline & \multicolumn{2}{|c|}{ Mean rank } & \multicolumn{2}{|c|}{ Mean rank } & $z$ & p-value \\
\hline QOL general & \multicolumn{2}{|c|}{16.35} & \multicolumn{2}{|c|}{24.65} & -2.368 & $0.018^{*}$ \\
\hline
\end{tabular}

$\mathrm{DP}=$ standard deviations; $\mathrm{M}=$ means; $\mathrm{QOL}=$ quality of life; $t$ and $z=$ degrees of freedom

$*_{\mathrm{p}}<0.05$

Table 6. Student's $t$-test for the four domains of quality of life and Mann-Whitney test for general quality of life according to different degrees of social support.

\begin{tabular}{|c|c|c|c|c|c|c|}
\hline & \multicolumn{2}{|c|}{ Better social support $(n=27)$} & \multicolumn{2}{|c|}{ Worse social support $(n=13)$} & \multirow[b]{2}{*}{$t$} & \multirow[b]{2}{*}{ p-value } \\
\hline & M & DP & $\mathbf{M}$ & DP & & \\
\hline \multicolumn{7}{|c|}{ Domains of quality of life } \\
\hline Physical & 16.83 & 2.027 & 14.22 & 2.120 & 3.764 & $0.001 * *$ \\
\hline Psychological & 17.30 & 1.633 & 14.91 & 1.733 & 4.263 & $0.00 * *$ \\
\hline Social relationships & 17.88 & 1.569 & 14.46 & 2.859 & 4.024 & $0.001 * *$ \\
\hline Environment & 15.82 & 1.885 & 14.27 & 2.386 & 2.234 & $0.031 *$ \\
\hline & \multicolumn{2}{|c|}{ Mean Rank } & \multicolumn{2}{|c|}{ Mean Rank } & $z$ & $\mathrm{p}$-value \\
\hline QOL general & \multicolumn{2}{|c|}{24.33} & \multicolumn{2}{|c|}{12.54} & -3.153 & $0.002 * *$ \\
\hline
\end{tabular}

$\mathrm{DP}=$ standard deviations $\mathrm{M}=$ means; $\mathrm{QOL}=$ quality of life; tand $z=$ degrees of freedom

$*_{\mathrm{p}}<0.05 ; * *_{\mathrm{p}}<0.01$

support - differences in all quality of life domains could be found only for the social support variable, with individuals who had better social support reporting a better quality of life (Table 6).

With regard to the considerable impact of social support on the quality of life shown by our congenital heart disease patients, we decided to further analyse the relationship between this variable and the severity of the disease. Thus, Table 7 shows that patients with complex congenital heart disease and a better social support presented a better perception of quality of life in every domain, highlighting once again the importance of this variable, social support, on the adaptation to the disease.

When the severity of congenital heart disease was minor to moderate, social support only influenced 
Table 7. Student's $t$-test for the four domains of quality of life and Mann-Whitney test for quality of life general taking into account the influence of social support in congenital heart disease severity complex.

\begin{tabular}{|c|c|c|c|c|c|c|}
\hline & \multicolumn{4}{|c|}{ Complex } & \multirow[b]{3}{*}{$t$} & \multirow[b]{3}{*}{ p-value } \\
\hline & \multicolumn{2}{|c|}{ Better social support $(n=13)$} & \multicolumn{2}{|c|}{ Worse social support $(\mathrm{n}=10)$} & & \\
\hline & $\mathbf{M}$ & DP & $\mathbf{M}$ & DP & & \\
\hline \multicolumn{7}{|c|}{ Domains of quality of life } \\
\hline Physical & 16.86 & 2.025 & 14.00 & 1.857 & 3.48 & $0.002 * *$ \\
\hline Psychological & 17.54 & 1.773 & 14.98 & 1.910 & 3.319 & $0.003 * *$ \\
\hline Social Relationships & 18.26 & 1.479 & 15.07 & 2.935 & 3.144 & $0.008 * *$ \\
\hline Environment & 15.86 & 2.052 & 13.70 & 2.137 & 2.455 & $0.023^{*}$ \\
\hline & \multicolumn{2}{|c|}{ Mean rank } & \multicolumn{2}{|c|}{ Mean rank } & $\mathrm{z}$ & p-value \\
\hline QOL general & \multicolumn{2}{|c|}{15.31} & \multicolumn{2}{|c|}{7.70} & -2.795 & $0.005 * *$ \\
\hline
\end{tabular}

Table 8. Mann-Whitney U-test for the four domains of quality of life and the quality of life general taking into account the influence of social support in congenital heart disease severity minor or moderate.

\begin{tabular}{|c|c|c|c|c|}
\hline & \multicolumn{2}{|c|}{ Minor or moderate } & \multirow[b]{3}{*}{$z$} & \multirow[b]{3}{*}{ p-value } \\
\hline & \multirow{2}{*}{$\begin{array}{l}\begin{array}{l}\text { Beter social } \\
\text { support }(n=14)\end{array} \\
\text { Mean rank }\end{array}$} & \multirow{2}{*}{$\begin{array}{l}\text { Worse social } \\
\text { support }(n=3) \\
\text { Mean rank }\end{array}$} & & \\
\hline & & & & \\
\hline \multicolumn{5}{|c|}{ Domains of quality of life } \\
\hline Physical & 9.64 & 6.00 & -1.15 & 0.25 \\
\hline Psychological & 10.18 & 3.50 & -2.107 & $0.035 *$ \\
\hline Social relationships & 10.50 & 2.00 & -2.696 & $0.007 * *$ \\
\hline Environment & 8.93 & 9.33 & -0.127 & 0.899 \\
\hline QOL general & 9.43 & 7.00 & -0.818 & 0.413 \\
\hline
\end{tabular}

the psychological and social relationship domains, with patients with better social support having a better perception of quality of life in these domains (see Table 8).

\section{Discussion}

An intriguing finding of our study is that our patients presented a better perception of quality of life for the psychological, social relationship, and environment scales, when compared with the healthy population. This may be striking, especially when we consider the severity of congenital heart disease and its symbolic impact on the patient and family. However, in previously conducted studies as well, congenital heart disease patients showed better or an identical quality of life as compared with the normal population. ${ }^{12,13}$

This resulting pattern can be probably explained by the mediating effect of several other factors, such as the family environment, social support, and personal resources. The fact that these patients require a significant amount of additional care as a consequence of their disease and its underlying implications gives rise to a protective and cohesive family environment that favours adaptation and acceptance of the disease, having a positive relationship with quality of life. ${ }^{7,15}$ They may also be surrounded by efficient social resources, namely social support, health resources, and opportunities to acquire new skills, during different time periods, considering the limitations they may have.

Both family environment and social support have a strong influence over personal resources, namely in the coping dimension and in the subjective wellbeing. ${ }^{15,16}$ A positive family environment with high cohesion, good expressiveness, and little conflict within the family, as well as an efficient social support, makes it easier for the individual to develop coping mechanisms focused on problem solving and on the positive reassessment of events, functioning as a factor of adaptation to the disease, ${ }^{16}$ which contributes 
to a satisfactory quality of life. However, adverse family relationships and parental stress are negatively related to the psychosocial dimensions of quality of life; ${ }^{15,17}$ therefore, the side effects of cardiac diseases can be compensated by a socially integrated family environment, with enough resources to provide a better quality of life for patients. ${ }^{7}$

Family environment and social support also have a strong impact on the patient's psychological adjustment. Previous studies stressed social resources as determinant factors for understanding the individual instability regarding the incidence of depressive symptoms and the reduction of disease-related distress. ${ }^{16}$

As far as demographic variables are concerned, older patients in our study presented a better perception of quality of life in the psychological domain. This finding is not consistent with data from other authors which suggests that older age is associated with a decrease in quality of life. These data are probably caused by rising concerns about the influence of congenital heart disease on matters such as employment, financial sustainability, and autonomy, as life goes on, leading to a stronger feeling of vulnerability. ${ }^{18,19}$

A possible explanation for the inconsistency between our findings and those mentioned in the literature may be related to the fact that the age range in our study was restricted to adolescence and young adulthood; the younger patients were in adolescence, 12-18 years of age, a life stage characterised by irreverence and the will to experience new feelings, and focused on activities with the peer group and on the conquest of independence from parents. Congenital heart disease patients have some limitations, such as reduced physical ability, that prevent them from performing certain activities; therefore, they may present with lower self-esteem $^{18,19}$ and a worse perception of quality of life for the psychological domain.

On the other hand, the patients' vulnerability encourages their parents to adopt overprotective educational styles that limit their social experiences, resulting in an impoverishment of their quality of life when compared with their peer group, $8,20,21$ which has an added importance in these age groups.

With regard to clinical variables, our findings show that the patients admitted to surgery presented a worse perception of quality of life for the physical domain when compared with those who had not been admitted to surgery. This association may be explained by the daily life restrictions and side effects that usually appear after the surgery and that limit physical performance, thus preventing physical activity. ${ }^{10}$ Yet, patients admitted to more than one surgery had a lower perception of quality of life in the same domain, physical, which can be explained by the fact that they feel more fragile because they need a greater amount of additional care ${ }^{10}$ and experience a higher number of situations of pain and discomfort, as well as restrictions to their daily life activities, because of hospital admissions.

As far as the residual lesions are concerned, patients who had severe-to-moderate lesions had a worse perception of the general quality of life for the physical and psychological domains, when compared with individuals with light residual lesions. Other authors advocate that the severity of disease has a negative impact on the patients' lives only when it is measured in terms of functional capacity. ${ }^{4}$ Patients with severe residual lesions are perhaps those who are functionally more compromised, whose daily routines are more limited, and are hence possibly invaded by negative feelings, low self-esteem, and frustration, which has implications on quality of life.

Finally, regarding psychosocial variables, which may function as compensatory mediating factors for the severity of disease, we have found that social support has a substantial positive influence in the perceived quality of life in every domain, and this variable is particularly important in the more severe congenital heart disease, a fact that is backed by literature.

Previously published papers state that the side effects of cardiac diseases can be compensated for by a socially integrated family environment. ${ }^{7}$ Others explain that social resources are determinant factors for understanding the individual instability regarding the incidence of depressive symptoms and the reduction of disease-related distress. ${ }^{16}$ Social support, however, has a strong influence over personal resources, namely on the coping dimension and on the subjective well-being. ${ }^{16}$

Consistent with this hypothesis we found that, in spite of the complex severity of the cardiac disease, patients with good social support presented a satisfactory perception of quality of life. Social support, however, does not have the same impact on cardiac diseases with minor-to-moderate severity, although it still has a strong positive influence on the perceived quality of life in the psychological and social relationship domains. These findings allow us to assume that our congenital heart disease patients have an efficient social support system functioning as a compensatory factor for the severity of congenital heart disease and that social support also contributes to these patients developing internal mechanisms that allow them to face the adversities of the disease.

\section{Conclusion}

The congenital heart disease patients of our study had a better perception of quality of life for the psychological, social relationship, and environment domains compared with the general healthy population. Regarding the demographic variables, 
older individuals had a better perception of quality of life for the psychological domain. As far as the clinical variables are concerned, only severe and moderate lesions, and the need and greater number of surgical procedures, had a negative impact on the perceived quality of life for these patients.

Finally, it may be concluded that social support functioned as a resilience factor in the acceptance and adaptation to the disease, with a special contribution in cardiac diseases of higher severity.

\section{Acknowledgements}

This work was supported by a grant from CESPU Cooperativa de Ensino Superior, Politécnico e Universitário.

\section{References}

1. Almeida JP. Impacto dos factores psicológicos associados à adesão terapêutica, ao controlo metabólico e à qualidade de vida em adolescentes com diabetes tipo 1 . Tese de Doutoramento. Universidade do Minho, 2003.

2. Horowitz ES. Insuficiência cardíaca nas cardiopatias congénitas do adulto (CCA). Revista da Sociedade de Cardiologia do Rio Grande do Sul 2004; 3: 1-3.

3. Vaz DD, Silva $\mathrm{CH}$, Gomes LF (s/d). Qualidade de vida em crianças e adolescentes com cardiopatia congénita por meio do CHQ-PF 50-Child Health Questionnaire. Recuperado em 18 Março, 2009, de http://www.propp.ufu.br/revistaeletronica/.../ vida2005/qualidade

4. Moons P, Van Deyk K, Marquet K, et al. Individual quality of life in adults with congenital heart disease: a paradigm shift. Eur Heart J 2005; 26: 298-307.

5. Latal B, Helfricht S, Fischer JE, Bauersfeld U, Landolt MA. Psychological adjustment and quality of life in children and adolescents following open-heart surgery for congenital heart disease: a systematic review. BMC Pediatr 2009; 9: 1-10.

6. Lawoko S, Soares JJF. Quality of life among parents of children with congenital heart disease, parents of children with other diseases and parents of healthy children. Qual Life Res 2003; 12: 665-666.

7. Goldbeck L, Melches J. Quality of life in families of children with congenital heart disease. Qual Life Res 2005; 14: 1915-1924.
8. Kamphuis M, Ottenkamp J, Vliegen HW, et al. Health related quality of life and health status in adult survivors with previously operated complex congenital heart disease. Heart 2002; 87: 356-362.

9. Krol Y, Grootenhuis MA, DestrÉe-Vonk A, Lubbers LJ, Koopman HM, Last BF. Health related quality of life in children with congenital heart disease. Psychol Health 2003; 18: 251-260.

10. Lane DA, Lip GYH, Millane TA. Quality of life in adults with congenital heart disease. Heart 2002; 88: 71-75.

11. Spijkerboer AW, Utens EMWJ, De Koning WB, Bogers AJJC, Helbing WA, Verhulst FC. Health-related quality of life in children and adolescents after invasive treatment for congenital heart disease. Qual Life Res 2006; 15: 663-673.

12. Fekkes M, Kamphuis RP, Ottenkamp J, et al. Health-related quality of life in young adults with minor congenital heart disease. Psychol Health 2001; 16: 239-250.

13. Moons P, Van Devk K, Marquet K, et al. Qualiy of life in adults with congenital heart disease: better than expected? Gedrag \& Gezondheid: Tijdschrift voor Psychologie en Gezondheid 2006; 34: 209-222.

14. Vaz Serra A, Canavarro MC, Simão MR, et al. Estudos psicométricos do instrumento de avaliação da Qualidade de Vida da Organização Mundial de Saúde (WHOQOL-Bref) para Português de Portugal. Psiquiatria Clínica 2006; 27: 41-49.

15. Landolt MA, Buechel ERV, Latal B. Health-related quality of life in children and adolescents after open-heart surgery. J Pediatr 2008; 152: 349-355.

16. Coelho M, Ribeiro J. Influência do suporte social e do coping sobre a percepção subjectiva de bem-estar em mulheres submetidas a cirurgia cardíaca. Psicologia Saúde \& Doença 2000; 1: 79-87.

17. Majnemer A, Limperopoulos C, Shevell MI, Rohlicek C, Rosenblatt B, Tchervenkov C. Health and well being of children with congenital cardiac malformation, and their families, following open-heart surgery. Cardiol Young 2006; 16: 157-164.

18. Saliba Z, Butera G, Bonnet D, et al. Quality of life and perceived health status in surviving adults with univentricular heart. Heart 2001; 86: 69-73.

19. Ternestedt BM, Wall K, Oddsson H, Riesenfeld T, Groth I, Schollin J. Quality of life 20 and 30 years after surgery in patients operated on for tetralogy of Fallot and atrial septal defect. Pediatr Cardiol 2001; 22: 128-131.

20. Uzark K, Jones K, Slusher J, Limbers CA, Burwinkle TM, Varni JW. Quality of life in children with heart disease as perceived by children and parents. Pediatrics 2008; 121: 1060-1067.

21. Daliento L, Mapelli D, Volpe B. Measurement of cognitive outcome and quality of life in congenital heart disease. Heart 2006; 92: 569-574. 